\title{
Erratum to: Socio-Demographic Vulnerability: The Condition of Italian Young People
}

\author{
A. Busetta $\cdot$ A. M. Milito
}

Published online: 3 February 2010

(C) Springer Science+Business Media B.V. 2010

\section{Erratum to: Soc Indic Res \\ DOI 10.1007/s11205-009-9507-9}

After the article has been published Online First, the authors discovered a big typo in Fig. 2 of the paper. In fact the authors realized that an old version of the graph had been used. The authors are sorry for this trouble that makes the online version of the paper seriously "unclear" and inconsistent with the explanation in the text.

Below you will find the right figure.

The online version of the original article can be found under doi:10.1007/s11205-009-9507-9.

A. Busetta $(\bowtie) \cdot$ A. M. Milito

Department of Quantitative Methods for Human Sciences, University of Palermo, Palermo, Italy e-mail: abusetta@unipa.it
A. M. Milito
e-mail: milito@unipa.it 
Fig. 2 The socio-demographic vulnerability quadrant

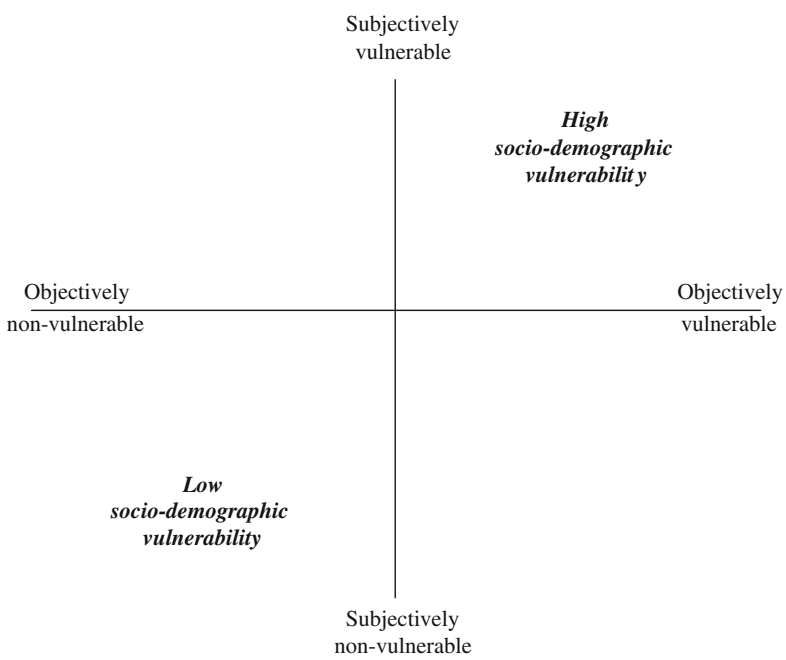

